\title{
Teologia e Universidade: considerações históricas e apontamentos para uma fecunda convivência
}

\author{
Theology and University: historical considerations \\ and notes for a fruitful coexistence
}

\section{Teología Y Universidad: consideraciones históricas y notas para una convivencia fructífera}

\author{
Vanessa Rossi Americano* \\ Reuberson Rodrigues Ferreira**
}

\begin{abstract}
RESUMO
O presente artigo tem por objetivo apresentar a relação entre Teologia e Universidade. Faz-se uso do surgimento das universidades na Idade Média para justificar a histórica relação entre ambas. Aponta-se que o estudo de teologia e o ambiente próprio da Europa medieval favoreceram o despontar das associações - universitates - como centro de aglomeração de saber. As vicissitudes históricas, as conjunturas políticas e as perspectivas epistemológicas fizeram com que eclodisse uma cisão entre ambas, a tal ponto de Teologia e Universidade percorrerem caminhos opostos, não raras vezes, beligerantes. Atualmente, busca-se apresentar a teologia como um elemento possível na academia, com metodologia e epistemologia plausíveis, que gozam de cidadania acadêmica efetiva.

Palavras-chave: Universidade; teologia; história; ciência.
\end{abstract}

\begin{abstract}
This article aims to present the relationship between Theology and the University. The emergence of universities in the Middle Ages is used to justify the historical relationship between the two. It is pointed out that the study of theology and the environment of medieval Europe favored the emergence of the associations - universitates - as a center of agglomeration of knowledge. The historical vicissitudes, the political conjunctures and the epistemological perspectives caused a break up between the two, to such a degree that Theology and the University went on opposite paths, not infrequently belligerent. Curently, the theology is presented as a possible element in the academy, with plausible methodology and epistemology that enjoy effective academic citizenship.
\end{abstract}

Keywords: University; theology; history; science.

* Mestra em Educação pela Pontifícia Universidade Católica de São Paulo (PUC-SP), diretora de Escola na Rede Municipal de Educação em São Paulo. Email: americanovanessa@gmail.com

** Mestrando em Teologia na Pontifícia Universidade Católica de São Paulo (PUC-SP), especialização em Teologia, História e Cultura Judaica pelo Centro Cristão de Estudos Judaicos (CCEJ - SP) e docência do Ensino Superior pela Faculdade de Educação São Luís. E-mail: reubersonferreira@yahoo.com.br 


\section{RESUMEN}

Este artículo tiene como objetivo presentar la relación entre la teología y la Universidad. Se hace uso de la aparición de las universidades en la Edad Media para justificar la relación histórica entre los dos. Se señala que el estudio de la teología y el propio entorno de la Europa medieval favorecieron el surgimiento de asociaciones - universitates - como centro de la aglomeración saber. Las vicisitudes historias, circunstancias políticas y perspectivas epistemológicas han causado una división estallar entre ellos hasta el punto de Teología y Universidad deambulan caminos opuestas, a menudo, beligerantes. Actualmente, se busca presentar la teología como un posible elemento en la universidad, con la metodología plausible y epistemología que disfrutan de una ciudadanía académico efectiva.

Palabras clave: Universidad; teología; historia; ciencia.

\section{Introdução}

$\mathrm{Na}$ tragédia teutônica intitulada Fausto, obra de cunho teatral, escrita por Goethe (1749-1832) o personagem central, cujo nome dá título à obra, é um homem, embora muito descontente com isso, imensamente ilustrado. Insatisfeito com a formação intelectual e com os saberes adquiridos, ele se põe a reclamar das ciências conquistadas outrora, mas que agora lhe causam dissabores (non sense), entre elas a teologia, ensinada nas universidades medievais, ao lado de outras ciências liberais que formavam os doutores no medievo (Filosofia, Artes, Direito e Medicina).

Sobre a teologia, afirma Mefistófeles, travestido com o barrete e a capa do Doutor Fausto, ao jovem em busca de saber: Nela "há mil caminhos falsos, difíceis de evitar; há mil peçonhas tão ruins, que extraí-las o remédio é (...) foro impossível (...) Nessa ciência, o mais seguro é não pensar por si, mas jurar pelo mestre" (GOETHE, 2012, p. 105). Como alternativa à sua postura, o protagonista da tragédia alemã, põe em xeque sua alma, numa aposta com o demônio, Mefistófeles, em troca de um saber que faça sentido, na verdade um amor - o que ele não alcança. A despeito das interpretações literárias do texto, depreende-se desse ponto que, em Fausto, qualquer ciência deve, antes de tudo, dotar a realidade de sentido, de razões para viver, em última instância, de um amor, de uma paixão. Entendido, aqui, como capacidade de apresentar razões à sua própria existência.

Essa tragédia de versos rimados e métricos plastifica uma crítica que pode ser aplicada às ciências praticadas na atualidade. Destarte, qualquer ciência desprovida de uma razão causal que ofereça sentido à vida, à pesquisa e ao entendimento de mundo, seria desnecessária. A teologia, citada em Fausto como uma das ciências do universo acadêmico por ele apropriadas, sobretudo após o seu reconhecimento civil, a partir de 1999, tem que se apresentar hodiernamente com argumentos que imprimam sentido à sua existência e legitimidade epistemológica, sobretudo no âmbito da academia, da universidade. A essa problemática de modo particular esta pesquisa 
pretende apresentar, ao lado de tantos outros que já o fizeram, e inspirada por eles (DREHER, 2004; LIGORIO e PASSOS, 2011; SANTOS, 2006; PASSOS, 2006; ZEUCH, 2006), uma reflexão sobre a relação entre teologia e universidade na atualidade.

Para fins metodológicos, este artigo percorrerá, sumariamente, as raízes históricas da relação entre Teologia e Universidade, tanto num plano geral como no horizonte brasileiro. Ato segundo dessa pesquisa será demonstrar argumentos que legitimem a presença da Teologia na Universidade. Por fim, apresentam-se as inerentes conclusões indexadas a esse processo reflexivo. Acusa-se, ainda, que o viés trilhado para fundamentar os arrazoados aqui expostos será o da revisão da bibliografia acerca da temática: Teologia e Universidade.

\section{Teologia e Universidade: das origens à contemporaneidade}

Um olhar atento, persistente e agudo sobre os anais da história, revela uma relação de proximidade, parentesco, senão de gênese, entre Universidade e Teologia. Ambas estão de tal modo inextrincavelmente associadas, que é impossível, sob pena de certo obscurantismo acadêmico, compreender a primeira sem um olhar arguto sobre a segunda. Trata-se de uma relação longa, complexa e marcada por vicissitudes históricas, por paradigmas acadêmicos diversos e por cenários políticos intricados que ora favoreceram a justaposição, ora convergiram para uma irascível oposição e mútua exclusão entre ambas (PASSOS, 2016).

Sob o patrocínio de uma incursão histórica averígua-se, nos primeiros séculos da chamada baixa Idade Média, a consolidação das primeiras universidades, Bolonha e Paris, em 1174 (OLIVEIRA, 2007, p. 120). Seguida por outras, como Cambridge (1209), Oxford (1214), Salamanca (1220), Pádua (1222), Nápoles (1224), Toulouse, em 1288 (DREHER, 2004, p. 27). Todas elas nascem em plena cristandade, nos umbrais da Europa pautada por transformações. O continente europeu estava marcado por alterações profundas de cunho sociocultural, sobretudo devido à expansão comercial que, paulatinamente, lograra e se acentuara durante parte significativa da Idade Média.

A Europa (OLIVEIRA, 2007, p. 113-129), nesse período medieval, passou a ser o principal centro de urbanidade. Nela surge um número expressivo de pequenas cidades, em torno das quais a população vai, paulatinamente, se aglomerando e organizando. Igualmente e, de certo modo em decorrência desses pequenos centros, eclode uma zona crescente de livre comércio, com mercadores difusos por todo o continente. Concomitantemente, surgem as corporações de ofícios, as livres associações. Nesta perspectiva de livre 
associação é que despontam as universitates, também, como "uma forma de associação capaz de recolher os acúmulos culturais do passado e as novas condições do presente" (PASSOS, 2006, p. 22). Em torno do conceito de univeristates - pequenas associações - organizavam-se grupos de alunos com os seus mestres (SANTOS, 2006, p. 885-893) que, por meio desse instrumental corporativo, deliberavam sobre assuntos de interesses da comunidade acadêmica. Papéis como o do reitor, mediador dos interesses dos docentes e discentes com as autoridades eclesiásticas, bem como das faculdades, decorrem desse modelo de organização (SANTOS, 2006, p. 887).

As bases para o surgimento da universidade como centro de aglomeração de saber têm, contudo, suas raízes fincadas numa história muito mais longa. Os ambientes de estudos, que já estavam consolidados desde a baixa Idade Média e, geralmente associados às catedrais (escolas monacais/catedráticas e escolas urbanas), foram elementos de relativa importância para o florescer das academias. Elas conservaram os textos clássicos e desenvolveram com intensidade as artes liberais. Auferiram, assim, as condições de possibilidade para a fundação dessa instituição. A partir da fusão de conhecimentos já acumulados, bem como pelas novas realidades, já mencionadas, que eram vividas pelo ancien continente, é que surgem as centelhas do que será entendido, posteriormente, como universidade (PASSOS, 2006, p. 23). São esses elementos que, em boa medida, ofereceram as condições mínimas para uma prática acadêmica capaz de, à luz dos conhecimentos adquiridos e da realidade nova que vivia, consolidar as futuras universidades. Nesse sentido, assegura Passos: "Há que ressaltar, portanto, que as Universidades emergem quando uma composição social diferenciada daquela rural feudal colocou as condições de possibilidade - econômica, social, política e cultural - para a criação de uma associação em torno do saber" (Passos, 2006, p. 23).

De igual modo, deve-se dizer que a história da Teologia Cristã e das suas formulações convergiu para o despontar da Universitates, que se transformaram nas Universidades tempos depois. Nos primeiros séculos da Era cristã, Clemente (150-215) e Orígenes (185-254), seu sucessor, desenvolveram uma teologia baseada em conhecimentos filosóficos (DREHER, 2004, p. 5). Tratava-se da síntese inicial entre filosofia e a experiência de fé cristã ocorrida na "primeira escola teológica de que se tem notícia" (DREHER, 2004, p. 5). Bento de Núrsia (480-547), em 529, mesmo ano que Justiniano (428-565) destruiu a Academia Platônica, estabeleceu seu mosteiro em Monte Casino, que tinha, no centro, uma biblioteca que serviu de abrigo para textos clássicos bem como ambiente de estudo, cópia e difusão do conhecimento do mundo Antigo para o Ocidente. Associa-se a esse contexto o início das 
traduções para línguas vulgares das obras da Antiguidade, empreendidas por Boécio (420-524), e a consequente apropriação da filosofia delas resultantes (DREHER, 2004, p. 5). Assim, progressivamente, cria-se espaço para uma penetração maior da filosofia clássica grega no universo de reflexão da fé, consolidando uma teologia cristã. Que nos anos posteriores facultou elementos importantes, tanto para a Teologia como para o processo epistemológico desenvolvido pelas universidades.

Do contato com o neoplatonismo e com o aristotelismo, a teologia logrou algumas benesses, dentre elas uma clara metodologia dialética. Estabelecendo uma relação intensa e profícua entre Filosofia e Teologia, fonte da revelação e tradição filosófica, fé e razão (Fides et ratio). Essa técnica foi apropriada com maestria por notáveis do medievo, como Anselmo de Cantuária (1033-1109), sintetizada na clássica e conhecida expressão latina fides quarens intelectum e credo ut intelligam. Também Pedro Abelardo (1079-1142) e Bernardo de Claraval (1090-1153), para citar os mais exponenciais, seguiram com acuidade as sendas da reflexão dialética protagonizada pelo Bispo de Cantuária. Favorecendo a consolidação de uma metodologia própria do medievo, chamada de escolástica, que será importantíssima para a Teologia e decisiva, do ponto de vista metodológico, para as outras ciências e a própria universidade. Nesse sentido, atesta Dreher:

Baseados em 'autoridades', professores e estudantes desenvolveram um método que passou a ser o principal instrumento de seu labor universitário: a Escolástica. O intelectual que se vale da escolástica não é um mero intérprete de textos (livros), mas um criador de problemas que exigem reflexão, provocam seu pensamento e o levam a posicionar-se. Seus exercícios levam ao surgimento de enciclopédias ou de summas (DREHER, 2004, p. 27).

A partir desse método, gestado como síntese de postulados platônico-aristotélicos e da fé cristã, desponta uma nova forma de pensar a teologia: a Escolástica. Ela teve sua expressão mais evidente em teólogos como Tomás de Aquino (1225-1274), Duns Escoto (1266-1308) e Guilherme de Ockham (1285-1347), para citar apenas alguns que escreveram compêndios que partiam sempre da relação problema, reflexão e solução para o problema. Os três citados acima, por caminhos distintos, trilham sendas rumo a um mesmo destino.

Do exposto, é claro que Teologia e Universidade, nos primeiros séculos da Alta Idade Média, se interconectaram, dando origem uma a outra e, ao mesmo tempo, fornecendo instrumentais para atingirem status de cientificidade dentro do paradigma da época. Por um lado, a Universidade recebe uma sedimentada tradição iniciada na síntese entre sistemas filosóficos e fé 
cristã desde o século II, passando pelas escolas catedráticas, e fundamentada pela dialética escolástica. De igual modo, recebe desse método o caminho necessário para chegar à compreensão da verdade. Sob esse fundamento seguro, a filosofia, a medicina e o direito avançam como ciência e como formação de profissionais (PASSOS, 2016, p. 219-232).

Por outro lado, a Teologia, enquanto ciência acadêmica, reflexão da fé, nesse contexto se reinventa, amplia seu significado, gestando um "sistema teórico e metodológico coerente; sistema que organiza as principais questões da fé e fornece uma metodologia para sua investigação" (PASSOS, 2016, p. 225). Ambas se beneficiaram e gestaram um seguro ambiente para o desenvolvimento das ciências.

Distanciando-se, naturalmente, dos passos germinais, a Teologia e a Universidade vão se consolidando nas trilhas da história. A escolástica (PASSOS, 2006) torna-se paradigma oficial da reflexão teológica e condão de apoio do magistério da Igreja Católica para homogeneização da reflexão sobre a fé, bem como arma apologética contra os dissidentes. De igual forma, as universidades entram num processo de "rotinização" do seu carisma inicial, e ligam-se, cada vez mais, à autoridade católica (por elas controladas) e, com o passar do tempo, transformam-se num centro de reprodução e conservação de conteúdos passados. Um reduto eminentemente insípido às inovações.

Com o advento da modernidade e sua lógica racionalista, as críticas a esse modelo de universidade medieval e princípio metodológico da teologia fazem-nas soçobrar. As universidades modernas e o primado da razão técnico-científica, bem como as conjunturas sociopolíticas (separação entre Igreja e Estado) vão selando uma relação cada vez mais de distanciamento entre Teologia e Universidade. Esta última, considerada sempre mais como espaço do livre uso da razão, não acolhe mais aquela, que se tornara identificada, mais ainda, com o clero e com certo obscurantismo da razão pela fé. Teologia e as novas universidades firmaram um pacto implícito de mútua exclusão. Quiçá, numa perspectiva menos pessimista, um acordo de tolerância ou conveniência política.

$\mathrm{Na}$ atualidade, muito mais por conveniências ou acordos políticos, a Teologia ainda subsiste nos ambientes universitários. Na Alemanha, por exemplo, devido a históricos acordos entre autoridades eclesiásticas, são numerosas as escolas superiores de teologia credenciadas, dentro e fora das academias. "Existem trinta e uma Faculdades de Teologia em universidades públicas alemãs (...) Dezenove faculdades são vinculadas ao Protestantismo. Doze faculdades representam o Catolicismo" (URASKI, 2011, p. 150). 
Na França secularizada, há uma a situação similar à Alemanha, na região administrativa da Alsácia. Nesse lugar, encontram-se os "únicos casos de Teologia na Universidade (por serem as universidades estatais), as Faculdade de Teologia Protestante e Católica da Universidade Marc Bloch, Strasbourg II" (ZEUCH, 2006, p.7). Na Itália, após a unificação do país, os cursos de Teologia nas universidades públicas malograram, restando, atualmente, na grande maioria, cursos de Teologia em universidades do Estado Pontifício do Vaticano (cf. MARCCHIONNI, 2011, p. 163-170). Há outros países do continente Europeu nos quais a Teologia é ministrada nas universidades, particularmente as estatais, como é o caso do Reino Unido, da Espanha, Bélgica, para citar apenas alguns.

A América do Norte conta com mais de 1.470 instituições de estudos Teológicos, algumas alocadas em universidades renomadas, como Harvard, Columbia, Yale, Chicago (RIBEIRO, Jr., 2011, p.186-189). Na América do Sul, normalmente, as faculdades de Teologia, quando existem, estão adscritas em universidades confessionais e particulares. Elas, ao menos no Brasil, gozam de reconhecimento como área do saber credenciada junto aos organismos governamentais (ANDRADE, 2011, p. 29).

Sobre essa presença, sugere Zeuch (2006, p. 8), que se trata de um vínculo frágil e questionado em vários níveis. Afirma-se que a Teologia se insere no seio universitário simplesmente pelo vínculo histórico. Que sua abordagem metodológica pouco tem a oferecer ao mundo acadêmico. Não raro, ela é considerada uma espécie de ciência com uma racionalidade endógena, paralela ou secundária.

Largos traços, percebe-se que a relação entre Teologia e Universidade é longa e complexa. Uma história marcada por uma origem comum, que convergiu para uma oposição radical. Busca-se, na atualidade, uma síntese. Esta não pode ser por imposição ou conveniência, mas nos mesmos moldes daquela das origens, isto é, de proposição metodológica. Nesse sentido, caminhando para apresentar aspectos que facilitem essa síntese, é salutar observar a realidade brasileira no que diz respeito à Teologia e Universidade.

\section{Teologia e Universidade no Brasil}

A quase milenar história do surgimento da Universidade descrita acima, em meados do século XII, pouco tem a ver com a história dessas instituições no Brasil. Ela aportou de modo seminal, neste país continental, há não mais que trezentos anos, por interesses da Coroa Portuguesa, em forma de Cursos Técnicos Superiores. Sua consolidação, contudo, deu-se somente na República do Brasil, nas primeiras décadas do século XX. Verdadeiramente, trata-se de 
uma assunção tardia, em se comparando com a Europa e outras as colônias na América Latina, como as hispânicas, onde já haviam sido constituídas universidades na primeira metade do século XVI, nomeadamente no Peru.

A história da Universidade no Brasil, sinteticamente, gravita entre tentativas fracassadas de estabelecimento dessa instituição e a consolidação dela a partir da fusão de diversos cursos superiores. A formação em nível superior, incialmente, esteve adstrita a escolas politécnicas e academias reais. Esses cursos, fundidos a outros, após algumas tentativas frustradas, serão a base de formação das universidades no Brasil. A consolidação dessa instituição no país, contudo, será um processo longo e complexo.

Entre as tentativas fracassadas de consolidação da Universidade, encontram-se alguns episódios pitorescos. Dentre eles, no século XVI, na Bahia, ainda nos anos de colônia, os Jesuítas foram reprovados pela Santa Sé em seu intento de constituir uma Universidade no Brasil (COSTA \& RAUBER, 2009, p. 241-258; FAVERO, 2006, p. 17-36) nos mesmos moldes das Academias Pontifícias do Estado Vaticano e do Continente Europeu. De igual modo, em nível de intenções, figurava na agenda da Inconfidência Mineira a criação de uma Universidade (FAVERO, 2006, p. 17-36). Com o fracasso da revolução, o projeto soçobrou. Durante o Império, Dom Pedro II, “em sua última fala do trono (1989) [propõe] a criação de duas universidades, uma no norte, outra no sul, que poderiam se constituir centros de alta organização cientifica e literária" (FAVERO, 2006, p. 21). Proposição que não vigorou.

As primeiras iniciativas palpáveis de consolidação de cursos em nível superior no Brasil despontam com a mudança da Família Real para o país, nos idos de 1808 (FAVERO, 2006, p. 17-36). Com a vinda do Monarca para a colônia e a consequente mudança da sede do Reinado para o país, criaram-se instituições oficiais de ensino superior. No ano da vinda da Corte portuguesa foi instituído, na Bahia, o Curso Médico de Cirurgia e uma Escola Anatômica, Cirúrgica e Médica, no Rio de Janeiro. Outras instituições, como a Academia Real Militar e Faculdades de Direito (algumas alocadas nos claustros de mosteiros e conventos), foram fundadas nos anos seguintes do Reinado. Essas instituições, não obstante oferecessem uma formação sólida em nível superior durante o período da Colônia e do Império, não gozavam de uma definição clara de universidades.

Com a proclamação da República, despontaram alguns modelos livres de Universidades em Manaus (1909), São Paulo (1911) e no Paraná (1912). Elas fiavam-se da chancela dos governos estaduais. Tais instituições, conforme Favero (2006, p. 17-36), surgiram porque a constituição de 1889 eliminou a perspectiva exclusivista do poder central sobre as universidades, criando condições 
para que os estados pudessem constituir suas próprias instituições de ensino superior. Elas foram classificadas ou alcunhadas de instituições de ensino livre.

Contíguo a esses episódios, em 1920, despontará a primeira Universidade estabelecida pelo Governo Federal, a saber: a do Rio de Janeiro. Ela é fruto da aplicação, pelo presidente Epitácio Pessoa (FAVERO, 2006, p. 17-36), do decreto $n^{\circ}$. 11.530, que reorganizava o Ensino Superior na República e determinava, entre outras coisas, que, quando o governo julgasse oportuno, poderia fundir em "Universidade as Escolas Polytechnica e de Medicina do Rio de Janeiro, incorporando a ellas uma das Faculdades Livres de Direito" [sic] (CAMARA DOS DEPUTADOS. Decreto no. 11.530, de 18 de Março de 1915). Essa Universidade chamar-se-ia "Universidade do Rio de Janeiro". Tempos depois, "Universidade do Brasil" e, finalmente, "Universidade Federal do Rio de Janeiro - UFRJ” (COSTA \& RAUBER, 2009, p. 241-258).

Após a Constituição da Universidade do Rio de Janeiro, despontaram outras instituições regidas pelo mesmo princípio de fundação (fusão de cursos técnicos e de ensino superior). Entre elas, a Universidade de São Paulo (USP), e a Universidade do Distrito Federal (UDF), para citar apenas algumas. Ao fim da década de setenta, quase todos os estados brasileiros já gozavam de suas instituições Universitárias, "merecendo destaque os Estados do Rio Grande do Sul e Minas Gerais, com mais de uma universidade criada" (COSTA \& RAUBER, 2009, p. 241-258).

A tardia assunção da Universidade no cenário nacional, no início do século XX, reproduziu a já mencionada mútua exclusão entre Teologia e Universidade. Os princípios que regiam a constituição da Universidade e o ambiente demasiadamente influenciado pelo positivismo no qual elas foram concebidas tornaram impossível a proposição de cursos de Teologia no ambiente universitário.

A reflexão teológica já não gozava mais de seu prestígio e da credibilidade de outrora, face às universidades. O modelo moderno dessas instituições, plastificado no Brasil, já não concebia uma ciência que, no decorrer da história, dedicou-se mais a questões internas e confessionais. Assim, entre essas duas realidades que, no princípio, estiveram visceralmente ligadas, selou-se uma dissociação completa, logo nos primeiros anos da Universidade no Brasil.

Essa separação, contudo, deu-se a partir do surgimento dos modelos modernos de Universidade, que foram implementados no Brasil. Ao longo da história da Colônia e do Império brasileiro, entretanto, nas diversas proposições para a ereção de universidades neste continente, afirmava-se a Teologia como uma faculdade ao lado de outras, ao estilo do que ocorria nas universidades medievais (PASSOS, 2004). Ela, contudo, não conseguiu impor-se 
com uma metodologia e epistemologia relevantes no universo acadêmico sob a legislação educacional marcadamente positivista e iluminista (ANDRADE, 2011, p. 25) que se instalou no Brasil. Sendo, por isso, desconsiderada no processo de constituição das universidades.

Os cursos de teologia, não obstante essa condição, ingressaram no seio das universidades. Eles obtiveram seu espaço como cursos livres e/ ou reconhecidos apenas no fórum interno das instituições eclesiais, sem a devida validação do Estado Brasileiro. De igual modo, essa ciência foi inserida, sobretudo nas universidades pontifícias católicas, como disciplina obrigatória e, em certa medida, como diferencial dessas instituições que, como outras, visavam à formação de uma elite profissional e intelectual (PASSOS, 2006). Do ponto de vista acadêmico, um agravante sempre se impunha: a Teologia foi relegada a um ostracismo e vista como prescindível, em relação às demais ciências.

Nas últimas décadas, contudo, os cursos de Teologia no Brasil, geralmente alocados no bojo de universidades confessionais, adquiriram cidadania acadêmica e reconhecimento civil. Um processo longo, que remonta à segunda metade do século XX, foi instaurado até que se chegasse à oficialização desses cursos. Nos idos de 1967, tentou-se, pela primeira vez, o reconhecimento civil de um curso de teologia a ser criado na Universidade Federal de Juiz de Fora. A conjuntura político-educacional não favoreceu que ele fosse assentido, resultando na sugestão da criação de um departamento de Ciência da Religião na mesma Universidade (ANDRADE, 2011, p. 26). Os cursos de teologia alocados nos seminários e faculdades seguiam funcionando como cursos livres. A Ciência Teológica seguia sendo produzida sem, contudo, ter fórum civil.

Nessa mesma linha e, paradoxalmente, na contracorrente dos processos normais de validação e reconhecimento dos cursos universitários, a Teologia atingiu reconhecimento civil nos programas de pós-graduação (Mestrado e Doutorado), antes de ter a graduação da mesma matéria reconhecida. Essa situação ocorreu nos últimos anos de 1998. Ela, embora incomum, forjou condições para que, no ano seguinte, pelo parecer do Conselho de Ensino Superior 241/99, homologado pelo ministro Paulo Renato, fosse publicado no Diário Oficial. Com ele, os cursos de Teologia passariam a gozar da possibilidade de reconhecimento civil, desde que atendessem especificações como infraestrutura, composição de corpo docente, duração mínima de quatro anos e acervo bibliográfico próprio e disponível na instituição (ANDRADE, 2011, p. 28-31). A Teologia, doravante, legitimamente, teria condições de reencontrar-se com as universidades. 
Passado pouco tempo desse episódio, a Escola Superior de Teologia (EST), de São Leopoldo, RS, tornou-se o primeiro Curso de Teologia autorizado pelo MEC. Outros vieram na sequência. Alguns foram reconhecidos, outros desautorizados. Atualmente, há mais de cem instituições autorizadas pelo MEC a oferecer o curso de Teologia no Brasil, Bacharelado ou Licenciatura, nas modalidades presencial ou à distância (REDAÇÃO MUNDO DO VESTIBULAR, 2017). Dentre elas, segundo avaliação do MEC, destacamse algumas com a nota máxima, como é o caso do curso da Universidade Metodista de São Paulo, da Universidade Presbiteriana Mackenzie e das Pontifícias Universidades Católicas do Paraná, do Rio Grande do Sul e São Paulo. Importantes centros universitários que acolhem no seu bojo a Teologia como ciência acadêmica licitamente praticada no Brasil. Essa relação, não obstante, ainda precisa ser aprofundada e otimizada, criando condições para uma frutuosa convivência entre teologia e universidade.

\section{Teologia e Universidade: apontamentos para uma fecunda e relevante convivência}

Uma convivência frutuosa entre Teologia e Universidade ainda precisa ser desenhada e orientada de forma que ambas possam fecundar-se mutuamente e, em certo sentido, complementarem-se. A relação entre Teologia e Universidade, como demostrado, é eivada por um lastro histórico, amplo e complexo. Não poucas rusgas, cisões e máculas marcam a tez da coexistência entre essas duas realidades. De uma origem comum, por vicissitudes históricas, ambas trilharam sendas distintas e, não raras vezes, excludentes.

$\mathrm{Na}$ Europa, essa relação umbilical foi visível, palpável e, durante muito tempo, frutuosa. No continente Latino-americano, mormente no Brasil, ela nem chegou a ter uma aparência clara. Nas universidades públicas fundadas neste país não houve espaço para a ciência teológica. Ela, contudo, aportou nessa seara por um viés distinto, chancelada pelas universidades particulares e confessionais. Quase sempre foi percebida como uma ciência de racionalidade e lógica secundárias, dada mais à apologética que à investigação, bem como matéria de consumo interno de clérigos e religiosos.

A Teologia, pela legitimidade política que agora goza por conta da autorização para funcionar conferida pelos órgãos reguladores do governo, atingiu um novo patamar. Ela, doravante, tem permissão para circunscrever-se na esfera acadêmica. Sua legalidade política, sua sobrevivência nas universidades, contudo, ainda não lhe confere uma imprescindibilidade. Não raro, ela é considerada uma espécie de ciência com uma epistemologia endógena, paralela ou secundária. Tem inserção no seio universitário, para muitos, simplesmente 
por um desígnio político. Uma nova etapa para a permanência da Teologia nas universidades se impõe. Ela deve apresentar sua vitalidade epistemológica, sua contribuição para as diversas áreas do conhecimento.

A Teologia, mormente na realidade Brasileira, inserida no universo acadêmico para ser eficaz e proeminente, deve trilhar sendas específicas. Trilhas que, paulatinamente, façam de sua presença algo eficaz e com legitimidade (não só política) na academia. Condição essa que lhe permita travar diatribes, reforçar perspectiva e ampliar horizontes de compreensão dentro do universo próprio da produção de conhecimento, da elaboração de conteúdo. Acredita-se que esses princípios repousem entre a transdisciplinariedade, a autonomia eclesial ou religiosa e um serviço de crítica contundente a paradigmas teológicos que criem simulacros de deus e solapem a dignidade humana. Nesse sentido, o caminho a ser trilhado pela Teologia deve partir, primeiramente, de uma nova relação com a academia.

Para produzir uma relação frutuosa no bojo da academia, a Teologia já não deve ser, como outrora, aquela que tinha a pretensão de abrigar em suas vísceras a exclusividade da verdade. Doravante, ela deve portar-se como uma parceira das demais ciências na busca da verdade. A origem remota da teologia despontou, como se demostrou anteriormente, da necessidade de compreender aquilo que era professado como fé.

Para demonstrar essa finalidade, serviu-se de pressupostos filosóficos, do diálogo com a racionalidade do seu tempo e apresentou as bases de entendimento de sua fé consolidando, inclusive, uma metodologia própria. Assim, a Teologia tem, historicamente, uma inextrincável relação de diálogo com a razão e com a ciência. Desse modo, na atualidade, o caminho possível e frutuoso da Teologia na Universidade, enquanto ciência, deve ser o do diálogo com as outras ciências. Viés esse chamado de interdisciplinaridade e/ ou transdisciplinariedade (LIGÓRIO, 2011, p. 286-287). Ela tem muito, a partir dos princípios, a oferecer às outras ciências, como uma crítica formal ao modelo estabelecido de racionalidade (cada vez mais questionável). De igual modo, ela também tem muito a receber das outras ciências. Visto que a fé é vivida e entendida por um ser humano concreto real e a expressão dela, de forma inteligível, não pode prescindir de categorias históricas, sociológicas e políticas. A Teologia agregaria, assim, elementos de outras ciências à sua forma de apresentação e lograria uma configuração que poderia ser comunicada com muito mais robustez, pertinência e inteligibilidade ao homem sempre em perpétua transformação cultural e social. Nesse espírito, sobre a Teologia e sua presença na sociedade e na atualidade hoje, afirma Kuzma: 
Uma teologia que se entenda também como ciência e que procure se abrir às novas realidades deve entender e acolher tais avanços [da ciência, da sociedade] e dialogar através deles e com eles. Ela dever ver na opinião científica uma aliada favorável e não uma concorrente da verdade (KUZMA, 2011, p. 240).

Outra seara a ser cultivada pela Teologia para apresentar-se como relevante no campo universitário (entenda-se das ciências) é a independência e/ ou autonomia face às Igrejas. Historicamente, a Teologia consolidou-se como reflexão racional sobre os fundamentos da fé. Ela buscou ser a consolidação de um intelectus fidei. Sua busca fundamental e maior foi, à luz de problemas concretos humanos, apresentar, por meios racionais, os postulados de fé. Uma dialética que se consolidou, tempos depois, em uma metodologia específica, chamada Escolástica.

O decorrer do tempo colocou a Teologia não mais como aquela que busca a verdade, mas aquela que sustenta ou sedimenta conceitos eclesiológicos, quiçá em detrimento da busca pela verdade. Esses conceitos foram, normalmente, ditados por interesses do Magistério Eclesiástico e de decisões doutrinais de comissões e direções de Igrejas. Ante esse fato é que se afirma uma explícita necessidade de autonomia da Teologia em relação à Igreja, mesmo que uma separação radical seja um dado improvável, pela origem comum que ambas possuem (PASSOS, 2016, p. 80-93).

A Teologia, embora alocada, em grande parte de sua história, no bojo da Igreja, é uma produção cultural e intelectual. Como tal, uma vez lançada ao público, ganha fóruns que não são mais somente eclesiais, portanto públicos. Assim, sua construção, embora observada pelas autoridades eclesiásticas, não pode servir apenas para responder a interesses privados de comunidades religiosas e seus respectivos sistemas de crença. Ela deve, dentro e fora do ambiente universitário, primar pela busca da verdade e contribuir para que aqueles que professam uma determinada fé tenham cada vez mais clarividência daquilo que acreditam. Tenham certeza do discurso sobre Deus que professam e, com isso, encontrem ecos nas suas histórias e razoabilidade na sociedade. Assim, uma Teologia em ambiente universitário não pode restringir-se apenas a uma espécie de autofagia religiosa. Antes, ela deve ser o luminar que orienta, de forma clara e distinta, a real compreensão da fé e atualização dela face ao contexto e novos desafios diante dos quais o homem que crê é chamado a viver.

Por fim, a relação entre Teologia e Universidade será tão mais produtiva quanto possível se aquela apresentar a esta uma reflexão axiológica sobre a realidade. A Teologia deve, por isso, apresentar-se como uma "abordagem valorativa da realidade apresentada desde um horizonte de fé" (PASSOS, 
2016, p. 90). Caminho já trilhado por outras ciências que imprimem valores à realidade, como o direito, a ética e a educação. Assim, a ciência teológica galgaria o mesmo estatuto de outras ciências, mas argumentando desde seus postulados de fé.

Nesse sentido, a Teologia deve buscar, no meio universitário, apresentar-se a partir do seu locus reflexivo como uma ciência capaz de mensurar e valorar a realidade. Ela pode apresentar valores ético-morais que iluminem a realidade acadêmica e civil, como o fazem tantas outras ciências com suas descobertas e pesquisas. Essa capacidade pode ser utilizada tanto no plano interno das ciências universitárias como na sociedade em geral.

A Teologia, com sua racionalidade mais alocada no âmbito do sentido das coisas, pode ser uma crítica voraz ao racionalismo técnico-científico-pragmático das universidades, que não se preocupa com a finalidade das coisas e sobrepõe o fazer ao ser, o produzir ao conhecer. De igual modo, no plano da sociedade moderna, a Teologia pode analisar, do ponto de vista crítico, o discurso religioso e, em muitos aspectos, desconstruí-lo onde ele não se coaduna com a natureza daquilo que se crê de Deus. Nesse sentido, uma teologia ecológica, associada à ideia de um Deus criador, pode ser um forte instrumento contra a destruição da natureza; ou então uma Teologia Libertadora pode ser uma valiosa estratégia contra o discurso que legitima o empobrecimento e aumenta a separação (econômica, política e social) entre os povos. A Teologia, partindo de sua ampla tradição e de sua capacidade de apresentar a compreensão da fé de diversos modos, face às situações históricas, no seio da universidade pode ser a catalizadora de uma forte crítica (para o progresso) à sociedade contemporânea e ao meio acadêmico universitário.

\section{Conclusão}

À guisa de conclusão, retoma-se o poeta teutônico Goethe e recorda-se que a busca do personagem central da tragédia por ele escrita era pela felicidade, que ele não encontrara em nenhuma ciência das quais estudara, entre elas a Teologia. Entende-se que, para ele, as ciências deveriam operar sentido à vida. Elas deveriam ter um viés que justificasse seu estudo e razões que legitimassem sua existência.

Partindo desse pressuposto, o caminho percorrido nas páginas deste artigo buscou apresentar razões pelas quais a Teologia goza de sentido e necessidade no bojo das ciências Universitárias.

Esta pesquisa percorreu a história das relações entre Teologia e Universidade e reconheceu que ambas estiveram visceralmente ligadas. Ao longo de muitos anos, permaneceram associadas e fecundando-se mutualmente. As 
vicissitudes e as conjunturas político-sociais de épocas diversas concorreram para uma separação digna de uma irreconciliável reaproximação. As universidades modernas selaram esse afastamento, ao fazerem soçobrar os modelos medievais de Ensino Superior.

No Brasil, essa relação, nos primórdios das universidades neste país, já fora marcada pelo divórcio celebrado entre ambas no ancien continente. No decorrer do tempo, por caminhos diversos, Teologia e Universidade reaproximaram-se por um viés político, apresentado sob forma de decreto, que reconhecia a ciência teológica como área do conhecimento. Esse reconhecimento legou à Teologia o direito de readquirir cidadania acadêmica. Ele, contudo, requer ainda uma caminhada ampla de significação da Teologia no Universo acadêmico e de consolidação de sua posição.

Como viés de consolidação desse projeto, sugeriu-se a transdisciplinariedade, a autonomia em relação às Igrejas e a apresentação da Teologia como ciência valorativa. Três passos mínimos, que podem conduzir a Teologia numa caminhada maior de reconciliação com o universo acadêmico e de colaboração para a produção do conhecimento. Passos que, se bem dados, farão da relação entre Teologia e Universidade uma aliança profícua e frutífera.

\section{Referências Bibliográficas}

ANDRADE, Paulo Fernando Carneiro. O reconhecimento da teologia com saber universitário: Tensões e articulações entre as dimensões confessional e Profissional. In: LIGORIO, Afonso Maria Soares; PASSOS, João Décio (Orgs.).Teologia pública: reflexões sobre uma área de conhecimento e sua cidadania acadêmica. São Paulo: Paulinas, 2011, p. 21-36.

CAMARA DOS DEPUTADOS. Decreto n 11.530, de 18 de Marco de 1915. Disponível em: www2.camara.leg.br/legin/fed/decret/1910-1919/decreto-11530-18-marco-1915-522019-publicacao original-1-pe.html. Acessado em 06/02/2017 (19hs17).

COSTA, Everton de Brito Oliveira; RAUBER, Pedro. A história da educação: surgimento e tendências atuais. Revista Jurídica UNIGRAN, Dourados, v. 11, n. 2, p. 241-258, jan-jun, 2009.

DREHER, Martin. A teologia e origem da universidade. Cadernos de Teologia Pública, São Leopoldo, ano 1, n. 3, p. 3-32, 2004.

FAVERO, Maria de Lourdes Albuquerque. A universidade no Brasil: das origens à reforma Universitária de 1968. Educar. Curitiba. n.28. p.17-36,2006.

GOETHE, Johann Wolfgang von. Fausto. São Paulo: Montecristo Editora, 2012. (E-book). KUZMA, Cesar. A teologia no universo cientifico e sua especificidade epistemológica. In: LIGORIO, Afonso Maria Soares; PASSOS, João Décio(Orgs.). Teologia pública: reflexões sobre uma área de conhecimento e sua cidadania acadêmica. São Paulo: Paulinas, 2011, p. 230-247.

LIGÓRIO. Afonso Maria. A teologia na universidade, como convém. In: LIGORIO, Afonso Maria Soares; PASSOS, João Décio(Orgs.). Teologia pública: reflexões sobre uma área de 
conhecimento e sua cidadania acadêmica. São Paulo: Paulinas, 2011, p. 277-289.

MARCCHIONNI, Antônio. A teologia nas universidades da Itália. In: LIGORIO, Afonso Maria Soares; PASSOS, João Décio (Orgs.). Teologia pública: reflexões sobre uma área de conhecimento e sua cidadania acadêmica. São Paulo: Paulinas, 2011, p. 163-170.

OLIVEIRA, Terezinha. Origem e memória das universidades medievais a preservação de uma instituição educacional. VARIA HISTORIA, Belo Horizonte, vol. 23, n. 37, p.113-129, jan-jun 2007. Disponível em: http://www.scielo.br/pdf/vh/v23n37/v23n37a07. Acessado em 02/01/2017.

PASSOS, João Décio. A legitimidade da teologia na universidade: do político ao acadêmico. Estudos de Religião, São Paulo, vol. 18, n. 27, p. 13-29. Jul-dez. 2004.

PASSOS, João Décio. Teologia na universidade: coisa eclesial ou coisa pública?. Revista de Estudos da Religião. São Paulo, ano 16, n. 01, p. 19-37, jan-abr 2016. 80-93. Disponível em: http://revistas.pucsp.br/index.php/rever/article/view/28439. Acesso em 30/12/2026. DOI: http://dx.doi.org/10.21724/rever.v16i1.28439.

PASSOS, João Décio. Teologia que fala à universidade. Revista de Cultura Teológica, São Paulo, vol. 14, n. 54, p. 19-37, jan-mar 2006.

RIBEIRO JR., José Claudio. Deus na terra do dólar: os estudos teológicos nos EUA. In: LIGORIO, Afonso Maria Soares; PASSOS, João Décio(Orgs.). Teologia pública: reflexões sobre uma área de conhecimento e sua cidadania acadêmica. São Paulo: Paulinas. 2011, p. 172-192.

REDAÇAO MUNDO DO VESTIBULAR. Melhores faculdades de Teologia. Disponível em: www.mundovestibular.com.br/articles/17501/1/Melhores-faculdades-de-Teologia/Paacutegina1.html. Acesso em 07/02/2017.

SANTOS, Eduardo Silva. Universidade e teologia. Teocomunicação, Porto Alegre, vol. 154, p. 885-893, dez. 2006.

URASKI, Frank. A situação atual das teologias católica e protestante na Alemanha: um levantamento básico. In: LIGORIO, Afonso Maria Soares; PASSOS, João Décio(Orgs.). Teologia pública: reflexões sobre uma área de conhecimento e sua cidadania acadêmica. São Paulo: Paulinas. 2011, p. 149-162.

Submetido em: 4-4-2017

Aceito em:7-6-2017 